\title{
How public ambulance arrivals impact on Emergency Department workload and resource use
}

Enrico Ferri, Laura Magrini, Marco Alfano, Michele Del Parco, Salvatore Di Somma

Department of Emergency Medicine, A.O. Sant'Andrea, La Sapienza University of Rome, Rome, Italy

\section{SINTESI}

Obiettivi: Esaminare l'impatto del sistema di emergenza territoriale (EMT) sulle risorse del DEA.

Metodi: Studio retrospettivo su pazienti ammessi al DEA dell'A.O. Sant'Andrea comparando caratteristiche delle visite ed elementi legati al consumo di risorse.

Risultati: I pazienti giunti al DEA con l'EMT hanno età più avanzata, tasso di ricovero più elevato, lunga perma-

\section{Background}

Overcrowding in the Emergency Department (ED) is a growing problem in many health care systems ${ }^{1}$. Of the 115.3 million ED visit in the United States in 2007 an estimated of 15.5 percent arrived at the ED by ambulance ${ }^{2}$.

Such patients tend to be older than the average ED patients, were more likely to have higher acuity illness, injury or mental health care disturbances, and require more resources, ranging from diagnostic tests and treatment performed to total time spent in the ED and hospital admission rate ${ }^{3-7}$. It has been reported that ambulance arrivals seems to be associated with socio economic status, urbanicity and time of day $^{7,8}$.

It has been estimated that at currently rate of ambulance use, the volume of ED ambulance transport could grow in the USA until 20.2 million in the next years 5 .

It implicates an increasing in ED workload, crowding and resource use $e^{4,6,9}$, a rising of the ED transport per ambulance, a growth of the licensed Emergency Medical Services (EMS) vehicles, longer nenza nel DEA, maggiore severità in caso di trauma e vengono classificati con codice di priorità alto al triage presentando maggiore tasso di ricovero presso le unita di terapia intensiva.

Conclusioni: I pazienti che accedono al DEA con l'EMT hanno un impatto significativo su uso di risorse, carichi di lavoro ed affollamento dei DEA.

transport times and longer out of service times for individual ambulance $e^{5,10}$.

Despite organizative $e^{4-6,9-11}$ and financial ${ }^{12-14}$ implication related to EMS in the ED, few studies exists to estimate the epidemiology of ED public EMS ambulance transport related visits and their impact on ED activity ${ }^{2-6}$

More precise knowdlege of the pattern of ambulance arrivals and differences between ambulance and walk in patients could elucidate their respective impacts on the ED crowding, workload and resource use.

This study examine some of clinical factors associated with ambulance use as compared to walk in mode of arrival to a medium / large academic urban Emergency Department in Italy.

\section{Methods}

This is a retrospective study of all visits to the S. Andrea Hospital Emergency Department from $1^{\text {th }}$ January to the 31 December 2007. S. Andrea Hospital is a 400 beds teaching hospital which provides emergency care for the suburban north east 



metropolitan area of Rome and surrounding areas. Rome, capital city of the Lazio Region, has a central public EMS that dispatches ambulances in all the city.

Each Rome's ED is in reference with public EMS ambulances coming from a determined area which extension and resident population is related to ED and hospital capacity and serve as a back up destination for diverted ambulances when the surrounding EDs are overcrowded. Patients may not dictate the ambulance destination.

S. Andrea Hospital does not provide care for obstetric patients and has not an heliport for air rescue.

We have compared EMS public ambulance visits with walk in patients visits. Private ambulance arrivals were excluded from analysis.

Data were obtained from the ED computer records. Every hospital in Rome provided with an ED has been supplied since the 1999 by the Lazio Regional Health Care Authority with an informatic system denominated GIPSE (Gestione Informazioni Pronto Soccorso Emergenza / Emergency Care Informations Management) to collect information about ED related activities and to create a surveillance system on Emergency Care ${ }^{15}$.

The informatic records include patients arrival mode ("walk in", pubblic ambulances, private ambulances, police, air medical transport), arrival times, triage level urgency, waiting times before the visit, defined age groups subdivision, defined reasons of ED visit (abdominal pain, chest pain, coma, convulsions, dispnoea, fever, intoxication, injury, non traumatic bleeding, other pain, psychiatric symptoms, other symptoms), radiographs, CT and consultation ordered in the ED, lenght of stay in the ED, patient disposition status (admitted, discharged home, transferred to another hospital, left without medical advice, deceased).

In the "walk in" mode patients walking in are included but also those coming by commercial or private vehicles.

Age is categorized by GIPSE into five groups $(<15$, $15-24,25-44,45-64,>64$ years).

Traumatic complaints are classified by cause of injury (domestic, work or road accidents and assault). Comparison focused on visit caracteristics (temporal factors, triage level urgency, age, injury related, mortality) and resource use (lenght od stay in ED, CT and consultation ordered in ED, admission rate).

Triage urgency level was established by a trained triage nurse on a four point acuity scale on the basis of the global triage model proposed from the
"Gruppo Formazione Triage" (GFT) ${ }^{16}$. Triage level acuity was classified into 4 groups: level 1 red code (emergent / resuscitation), level 2 yellow code (urgent), level 3 green code (semiurgent), level 4 white code (not urgent):

Level 1 patient has critical conditions with compromise of a vital function;

Level 2 patient has conditions that are potential threats to life or limb or sense function without compromise of a vital function;

Level 3 patient has conditions that should be evaluated by a physician, and might deteriorate or benefit from medical intervention but without potential threats to life or limb or sense function;

Level 4 patient has conditions without any risk of deterioration and could be referred for evaluation to other areas of health care system (outpatient clinic).

Level 1 and 2 have rapid access in the ED emergency area and the physician intervent is immediate in the first case and into ten minutes in the second one, while, for the level 3 and 4, expected waiting times are from thirty to sixty minutes and from one hundred and twenty minutes respectively.

The model proposed from the GFT has been adopted in the 2007 by the Lazio Regional Health Care Authority and has been imposed on every ED of the Lazio Region ${ }^{17}$.

Patient admission to the hospital wards is established by the emergency physician on the basis of patient's hospital medical care requirements independently from insurance status ${ }^{18}$. All the italian citizens are provided by the State with a pubblic sanitary insurance and for foreigners, while staying on italian territory, admission to urgent medical care is independent from insurance status and all the costs are charged by the Italian State ${ }^{18}$.

For ED care since the $1^{\text {th }}$ January 2007 it has been established a contribution of $€ 25$ for the patient triage level 4 (not urgent) at discharge ${ }^{19}$.

The resource use was measured by lenght of stay (time from registration to admission or discharge from the ED), admission rate from ED to hospital wards, CT imaging tests and consultation ordered from the ED. Laboratory findings were excluded from analysis because not available records of these tests in the database.

\section{Statistical Analysis}

Results are presented as mean \pm standard deviation for continuous variables and absolute and relative frequencies for discrete variables. Comparison be- 


\section{organizzazione e formazione}

\section{time access in ED}

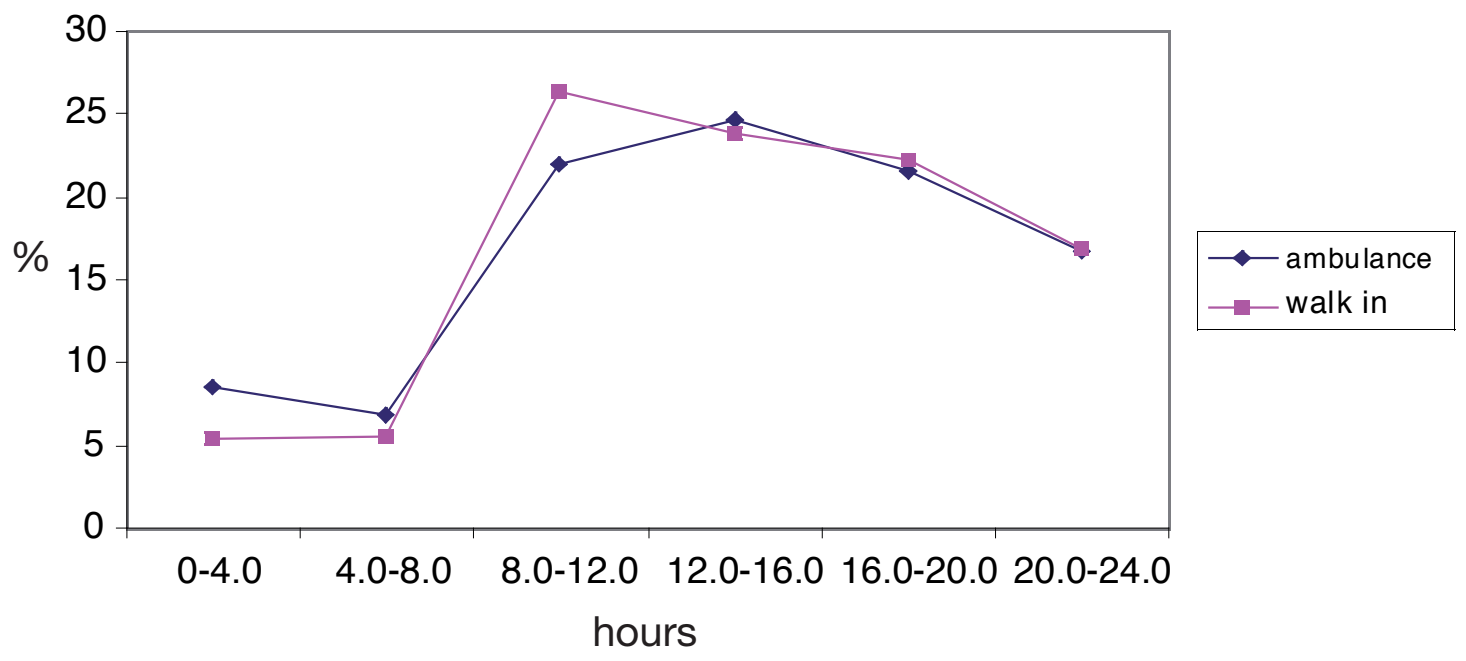

Fig. 1 - Time of ED arrivals for EMS ambulance transported and walk in patients.

ED ambulance arrivals trend in the year

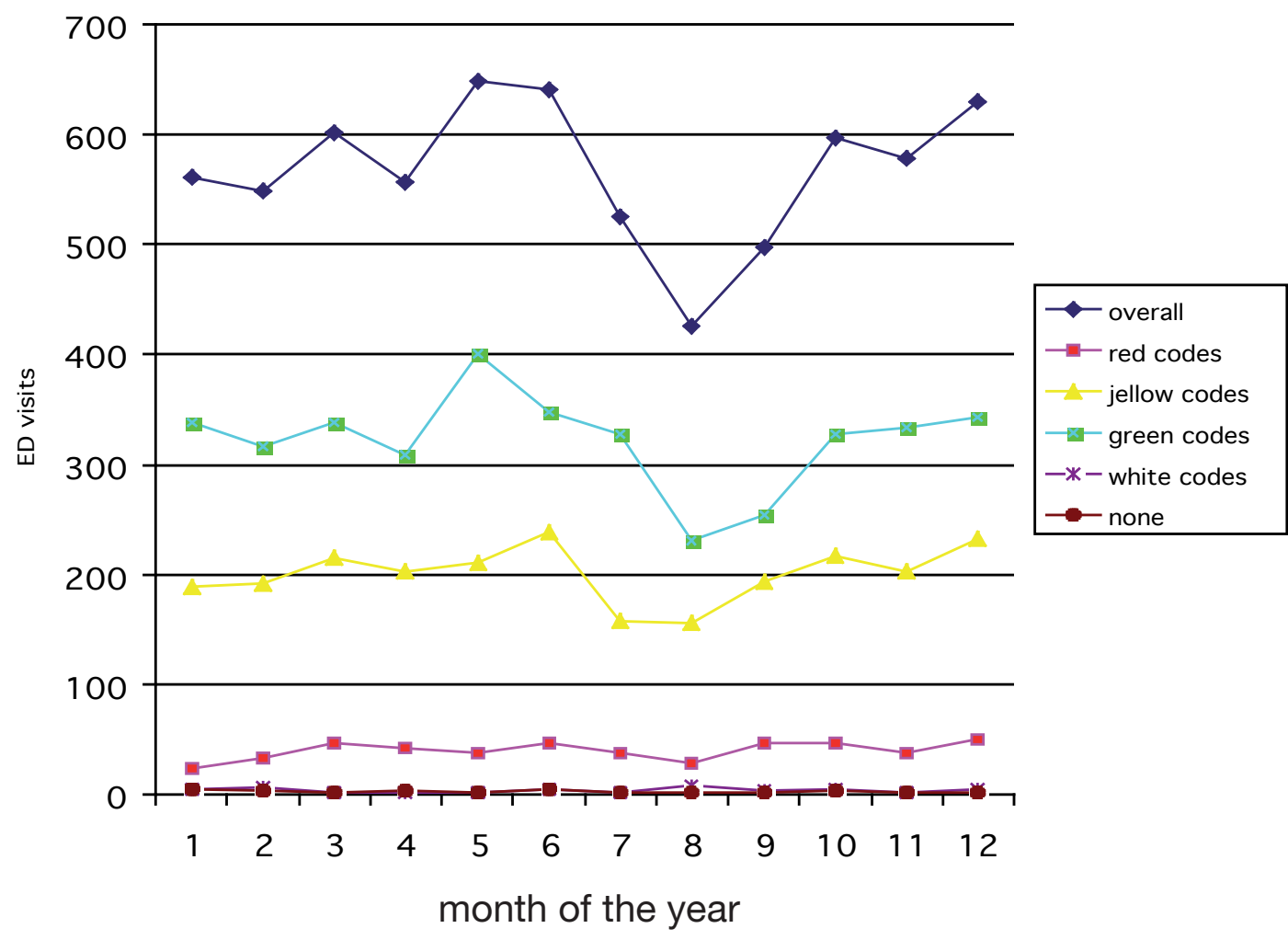

Fig. 2 - ED ambulance arrivals trend in the year. 
tween groups were performed using $\chi^{2}$ test with Fisher's exact test for discrete categorical variables and Student's t-test (unpaired) for continous normally distribuited variables.

A two-sided $\mathrm{P}<0.05$ was considered significant.

\section{Results}

In 2007 in S. Andrea Hospital ED there were 45.080 visits of which $14.9 \%$ (6750) arrived by public EMS ambulances, $83.52 \%$ (37.654) walk in and $1.49 \%$ (676) by private ambulance providers. The peak arrival time for the public EMS ambulance transports was from 12 aM to 4 PM but the diagram design in respect of walk in patients arrivals was roughly similar (Figure 1) and does not result any significative difference between the percentage of patients arriving at each time in the two groups $(p>0.5)$.

There were not relevant difference across day of the week, transport but also walk in ED visits being more consistently on Monday.
The colder period of the year (from November to February) is not associated to an increase rate of ambulance arrivals (Figure 2).

Patients transported by public EMS ambulances appeared to be more urgent than others (Table 1). The $42.64 \%$ transport cases were triaged as emergent or urgent $(7.03 \%$ triage level 1 and $35.61 \%$ triage level 2) and particularly relevant is the amount of patients on level 2 triage acuity code arrived by ambulances (Table 1 ).

Among triage 2 level classified patient the 35.61\% were referred by ambulance and only $12.51 \%$ walk in $(\mathrm{p}<0.0001)$ (Table 1$)$.

Among triage 3 level classified patient only 56.74\% were refferred by ambulances and the $80.37 \%$ were walk in ( $<$ 0.0007) (Table 1).

Determinants for visit were injuries in the $31.57 \%$ of patients which reached $37.48 \%$ (11.492/37.654) in the walk in against $30.51 \%(2530 / 6750)$ in the ambulance transported group (Table 2).

Pubblic EMS ambulance injury related arrivals result significantly more relevant on monday

\section{TAB. 1}

Triage level difference between ambulance transported and walk in ED patients.

EMS

Ambulance Transported

Walk in

\begin{tabular}{lrcrc}
\hline Triage level 1 & 475 & $7.03 \%^{*}$ & 108 & $0.28 \%$ \\
\hline Triage level 2 & 2.403 & $35.61 \%^{* *}$ & 4.711 & $12.51 \%$ \\
\hline Triage level 3 & 3.830 & $56.74 \%^{* * *}$ & 30.264 & $80.37 \%$ \\
\hline Triage level 4 & 42 & $0.62 \%$ & 2.421 & $6.42 \%$ \\
\hline Not performed & 0 & $0.0 \%$ & 152 & $0.40 \%$ \\
\hline$\Sigma$ & 6.750 & & 37.654 & \\
\hline
\end{tabular}

${ }^{*} \mathrm{p}<0.03 ;{ }^{* *} \mathrm{p}<0.0001 ;{ }^{* * *} \mathrm{p}<0.0007$

\section{TAB. 2}

Injury related visits and triage level difference between ambulance transported and walk in ED patients.

\begin{tabular}{lrrrr}
\hline & \multicolumn{2}{c}{$\begin{array}{c}\text { Injury } \\
\text { EMS Ambulance Transported }\end{array}$} & \multicolumn{2}{c}{ Injury } \\
Walk in
\end{tabular}

$\mathrm{p}=0.1 ;{ }^{* *} \mathrm{p}<0.0001 ;{ }^{* * *} \mathrm{p}<0.0001$ 
TAB. 3

Age difference between ambulance transported and walk in ED patients.

\begin{tabular}{lccrc}
\hline & \multicolumn{2}{c}{ EMS } & \multicolumn{2}{c}{ Walk in } \\
\hline$<15$ & 249 & $3.6 \% *$ & 6.723 & $17.85 \%$ \\
\hline $15-24$ & 675 & $10 \%$ & 4.129 & $10.9 \%$ \\
\hline $25-44$ & 1.912 & $28.3 \%$ & 11.618 & $30.85 \%$ \\
\hline $45-64$ & 1.406 & $28.8 \%$ & 7.793 & $20.69 \%$ \\
\hline$>64$ & 2.508 & $37.1 \% * *$ & 7.391 & $19.6 \%$ \\
\hline$\Sigma$ & 6.750 & $100 \%$ & 37.654 & $100 \%$ \\
\hline${ }^{*} \mathrm{p}<0,003 ;{ }^{* *} \mathrm{p}<0,01$ & & & &
\end{tabular}

and thursday respect to tuesday and wednesday (monday versus tuesday $\mathrm{p}=0.010$; monday versus wednesday $\mathrm{p}=0.037$; tuesday versus thursday $\mathrm{p}=0.015)$.

There is not any other significantly difference in the injury related pubblic EMS ambulance arrivals group between the other week days.

The percentage of injury related ambulance trasported patients does not rise on the week end; none difference emerged from week end days and weekly days injury related pubblic EMS ambulance arrivals.

Comparing arrival mode and triage level subgroups of injury related visits a relevant amount of ambulance trasported are classified at triage evaluation as level 1 or 2 acuity codes while walk in injuried patient are be more likely to be classified as semiurgent level 3 triage acuity code (Table 2 ).

The $26.91 \%$ of injuried patient referred by ambulance were triaged as urgent against $4.52 \%$ $(\mathrm{p}<0.0001)$ of walk in. Therefore the $92.26 \%$ of level 3, semiurgent, injuried related visits originate from walk in patients against $68.57 \%$ of ambulance transported $(\mathrm{p}<0.0001)$.

The proportion of ED visit in which the patient arrived by ambulance varied by patient age being significantly more consistent in the over 64 years old patients. The $37.1 \%$ of ambulance transported patients are over 64 years against $19.6 \%$ of walk in $(\mathrm{p}<0.01)$ (Table 3). The global admission rate from our ED has been $14.50 \%$.

The $35.7 \%$ of transported by ambulance have been admitted in hospital, $27.5 \%$ in our ED hospital and $8.2 \%$ transferred in other Istitution, against $14.47 \%$ of walk in patients $(\mathrm{pn}<0.0001)$ (Table 4) but in the over 64 years ambulance transported, admitted percentage rise to $59.76 \%$ (Table 4 ) against $43.88 \%$ $(\mathrm{p}<0.035)$.
ED mortality was $0.8 \%$ in the public EMS ambulance arrivals (54/6750) and 0.042\% (16/37.654) in the walk in group $(\mathrm{p}<0.00001)$.

Imaging CT scans and consultations were requested in 43.14\% (2912/6750) and in 48.28\% (3259/6750) in the EMS group respect to $8.71 \%$ (3283/37654) and 9.58\% (3608/37.654) of walk in counterparts (CT scans EMS versus walk in $p<0.0001$; consultations EMS versus walk in $\mathrm{p}<0.0001)$.

LOS in ED was quite different by ED access mode : 322.9 $\pm 363-7 \mathrm{~min}$. in the EMS ambulance referred patients and $155.7 \pm 232.7 \mathrm{~min}$. in the walk in group $(\mathrm{p}<0.0001)$.

The rate of admission in Intensive Care (ICU) or Coronary Acute Care Unit is significative different between ambulance and walk in patients (Table 5).

\section{Discussion}

In 2007 there were approximately 115.3 million ED visit in the USA which correspond to about 39.6 visits per 100 persons and on average roughly 30.000 visits per ED. The number of visits increased of 31 percent from the $1995^{2}$.

The 15.5 percent of visits arrived at the ED by ambulance ${ }^{2}$.

This represents 17.9 million ambulance transports, which has increased about 25\% from 14.3 million ambulance transports in $1997^{2}$.

Neverthless, little has been published on estimates of transported cases in ED overall activity ${ }^{2-7}$.

Some attention has been addressed to ambulance contribute at ED overcrowding and to economic, ethic and public policy related consideration to diversion ${ }^{12,20-22}$ but understanding the extent of effects related to ambulance cases and resources involved in, is important for ED and EMS organiza- 
TAB. 4

Hospital, Intensive Care Unit and Coronary Acute Care Unit admissions by ED access mode.

\begin{tabular}{|c|c|c|c|c|}
\hline \multirow[b]{2}{*}{$<15$} & \multicolumn{2}{|c|}{$\begin{array}{c}\text { EMS } \\
\text { Ambulance Transported } \\
\text { Admitted }\end{array}$} & \multicolumn{2}{|c|}{$\begin{array}{l}\text { Walk in } \\
\text { Admitted }\end{array}$} \\
\hline & 68 & $3.64 \% *$ & 651 & $14.27 \%$ \\
\hline $15-24$ & 104 & $5.57 \%$ & 224 & $4.91 \%$ \\
\hline $25-44$ & 269 & $14.43 \%$ & 690 & $15.12 \%$ \\
\hline $45-64$ & 309 & $16.57 \% * *$ & 995 & $21.81 \%$ \\
\hline$>64$ & 1.114 & $59.76 \%^{\circ}$ & 2.002 & $43.88 \%$ \\
\hline Overall admitted & 1.864 & $27.5 \%$ & 4.562 & $12.11 \%$ \\
\hline \multicolumn{4}{|l|}{ Transferred to other } & $2.36 \%$ \\
\hline$\Sigma$ & 2.420 & $35.7 \%^{\circ 0}$ & 5.454 & $14.47 \%$ \\
\hline Intensive Care Unit & $91^{\diamond}$ & $1.38 \%$ & 31 & $0.082 \%$ \\
\hline \multirow[t]{2}{*}{$\begin{array}{l}\text { Coronary Care Unit } \\
\text { admitted } \\
\end{array}$} & $224^{00}$ & $3.31 \%$ & 266 & $0.70 \%$ \\
\hline & \multicolumn{2}{|c|}{$\begin{array}{l}\text { Total Ambulance Transported } \\
6.750\end{array}$} & \multicolumn{2}{|c|}{$\begin{array}{c}\text { Total Walk in Arrivals } \\
37.654\end{array}$} \\
\hline
\end{tabular}

${ }^{*} \mathrm{p}<0.017 ;{ }^{* *}$ N.S. $\mathrm{p}=0.4 ;{ }^{\circ} \mathrm{p}<0.035 ;{ }^{\circ} \mathrm{p}<0.0001 ;{ }^{\circ} \mathrm{p}<0.001 ;{ }^{\diamond} \mathrm{p}<0.001$

tion also in order to determine costs and to maximize resource allocation.

Ambulance transported cases affect not only input but also throughput and output ED workload variables $^{22}$ and generate substantial net revenues for the hospital and decreasing diversion may represent for some institutions a feasible financial strategy ${ }^{12,14,20}$.

In fact more than one-third of patients of 65 years of age and over arrived at the ED by ambulance $e^{4,5}$ and a higher proportion of visits of patients 65 years of age and over were triaged as emergent compared with all other age groups 5 .

However ambulance visits tended to be triaged as being more urgent overall ${ }^{3,4,6}$ and a higher rate of ambulance use has been found among patients seeking ED care for injury ${ }^{3,6,7}$ or mental health related reasons ${ }^{7}$.

The $12 \%$ of patients visited in ED in USA were admitted in the hospital, and among those admitted $41.6 \%$ were 65 years of age and older ${ }^{2,5}$. In the over 65 years group more than 40 percent arrived by ambulance ${ }^{4,5}$.

Age groups and discharge status analysis in an acute care hospital ED in Singapore demonstrated analogue trend with the $37.4 \%$ of patients arrived by ambulance resulting 60 years of age and older; the $53.7 \%$ of the same group resulted in hospital admission compared with 17,07 and $29.3 \%$ of the walk in cases ${ }^{3}$.

Data from prehospital care set indicate that ambulance calls made by individuals aged 60 years or older may account for $40 \%$ of all ${ }^{23}$.

Non surprisingly emergency medical incident rate among person aged 85 years or older has been calculated 3.4 times higher than that of persons aged 45 to 64 years $^{24}$ and ED mortality was higher in ambulance cases respect to walk in ${ }^{3,6}$.

Moreover, older persons use EMS than younger ${ }^{3,5}$ and a large rising of the ED ambulance arrivals can be expected by the increasing of older persons population ${ }^{5}$.

Ambulance transported patients are significantly more likely than others associated to hospital admission rate but also to ED longer lenght of stay $^{4,6,25,26}$, greater use of consultations and radiology imaging tests indipendent from age and triage urgency ${ }^{4}$ and hospital intensive care unit/operating room admission ${ }^{6}$. Our findings provide further evidence that ambulance referred patients are more likely triaged into a higher acuity category (Table 1). Injury related visits overall seems don't link with access mode but the EMS ambulance transported are more severely injuried and classified as emergent or urgent (Table 2).

Therefore only a few of the level 3, semiurgent 
injury related visits originate by ambulance transported patients (Table 2).

In our study the utlization of EMS ambulance confirm association to older age (Table 3), higher rate of hospital admission overall (Table 4) and in the elderly subgroup (Table 4), longer length of stay, greater imaging tests, and consultation consumption. Moreover our data show a greater intensive care unit and coronary care unit admission from ambulance arrivals; it may be due to a higher degree of severity of clinical presentation both for the medical and for trauma patients in the EMS ambulance trasported group (Table 5).

Length of stay can measure resource consumption given that unmeasured resorurces such ED staff and space are consumed in proportion of length of stay $^{4,27}$.

Physician may be influenced by ED arrival mode and involve more resources for patients transported by ambulance but association to older age, higher acuity category at triage and rate of hospital admission suggest that illness or injury severity is the determinat of the trend.

Although it was not our aim to determine the patient's ambulance use appropriateness, despite the concern about abuse and misuse of ambulanc$\mathrm{es}^{8,23,28}$, our findings of an higher acuity category, more severe injuries and an higher rate of hospital admission in the ambulance trasported group are not consistent with the perception of inappropriate use of ambulance.

Therefore ambulance arrivals influence ED input workload by increase patient volume and complexity, throughput by affect lenght of stay, use of human and thecnologycal resources and output because determine a greater admission rate and in some institution intensive care unit and operating room admission ${ }^{3-6,20,25,26}$.

It should be considered that ED throughput depend also on input and output factors and significant improvement in ED throughput is unlikely without taking measure to address variation of input and output factors ${ }^{29}$.

Furthermore we can expect greater costs from ambulance visits.

Indirectly because ambulance visits are roughly more urgent than others overall ${ }^{3,4,6}$ and average costs are associated with triage acuity scale level ${ }^{30}$ and directly due to patient casemix complexity ${ }^{31}$, the greater use of test and consultations $s^{4,6,32}$, length of stay, $4,6,25,26$ and greater overall ${ }^{3,4}$ and intensive care or operating room admission ${ }^{6}$.

Moreover specific predictor of ambulance use among patient who visited the ED is an household income 1.4 times lower than others and it has been hypotized also that an higher ED resource use in ambulance patients may be associate to greater EMS transport use by patient of lower socio economic status ${ }^{33}$.

\section{Limitations}

To our knowledge this is the first study that examines in Italy the relationship between public ambulance arrivals and ED workload and resource use.

Our study is limited in several way.

First, our hospital is a medium/large, academic, acute care hospital which provides emergency care for a large metropolitan area and our findings might not be extended to the other EDs in rural areas of our region or nation. Moreover, hospital systems vary greatly between countries, so data from our study may not be applicable everywhere and further evaluations are required to analyze, especially in Europe countries, ambulance arrivals in the EDs and to increase our knowledge about the effects of arrival modes on the EDs activities.

\section{Conclusion}

Our study confirms that ED ambulance referred patients are more likely triaged into a higher acuity category and are significantly more likely than others associated to older age, to hospital and intensive care unit or coronary care unit admission rate, but also to severity of injury, ED longer lenght of stay and greater use of radiology imaging tests and consultations.

The ED pubblic EMS ambulance transported may have a significant impact on ED resource use, workload and crowding, and pattern and epidemiology of ambulance arrivals might be used to review ED resource allocation, workplans and to compare the loads of different ED.

\section{References}

1. Bernstein SL, Asplin BL. Emergency Department crowding. Old problem, new solution. Emerg Med Clin N Am 2006; 24: 821837.

2. Nawar EW, Niska RW, Xu J. National Hospital Ambulatory Medical Care Survey: 2005 Emergency Department Summary, Advance Data 2007; 29(386): 1-32.

3. Seow E, Wong HP and Phe A. The pattern of ambulance arivals in the emergency department of an acute care hospital in Singapore. Emerg Med J 2001; 18: 297-299.

4. Marinovich A, Afilalo J, Afilalo M, Unger B, Giguère C, Léger R, et al. Impact of ambulance transportation on resource use in the emergency department. Acad Emerg Med 2004; 11(3): 312-315.

5. Burt CW, McCaig LF and Valverde RH. Analysis of ambulance transport and diversion among US emergency departments. Ann Emer Med 2006; 47(4): 317-326. 
6. Ruger JP, Richter CJ, Lewis LM. Clinical and economic factors associated with ambulance use to the emergency department Acad Emerg Med 2006; 13(8): 879-885.

7. Larkin GL, Claassen CA, Pellettier AJ, Camargo CA. National study of ambulance transports to United States emergency departments: the importance of mental health problems. Prehosp Disast Med 2006; 21(2): 82-90.

8. Kawakami C, Ohshige K, Kubota K, Tochikubo O. Influence of socioeconomic factors on medically unnecessary ambulance calls. BMC Health Service Research 2007, 7: 120

9. Innes GD, Stenstrom R, Grafstein E, Christenson JM. Prospective time study derivation of emergency physician workload predictors. CJEM 2005; 7(5): 299-308.

10. Patel PB, Derlet RW, Vinson DR, Williams M, Willis J. Ambulance diversion reduction: the Sacramento solution. Am J Emerg Med 2006; 24: 206-213.

11. Bond K, Ospina M, Blitz S, Friesen C, Innes G, Yoon P. Interventions to reduce overcrowding in emergency departments [Technology report no 67.4]. Ottawa: Canadian Agency for Drugs and Technologies in Health; 2006 [http://www.cadth.ca].

12. McCollen KJ, Richards CF, Daya M, Weathers CC, Lowe RA Ambulance diversion and lost hospital revenues. Ann Emerg Med 2006; 48(6): 702-710.

13. Williams RM. Ambulance diversion : economic and policy considerations. Ann Emerg Med 2006; 48(6): 711-712.

14. Falvo T, Grove L, Stachura R and Zirkin W. The financial impact of ambulance diversion and patient elopments. Acad Emerg Med 2007; 14(1): 58-62.

15. Delibera Giunta Regionale Lazio n. 7628 del 22.12.1998 “Attivazione del Sistema Informativo Emergenza Sanitaria, integrazione del Sistema Informativo Ospedaliero" [http://www.asplazio. it/asp_online/att_ospedaliera/sies_new/Sies.php?menu=s2] .

16. Gruppo Formazione Triage. Triage Infermieristico. Mc GrawHill. Milano, 2005.

17. Il Triage Ospedaliero. Gruppo Triage Lazio. Agenzia di Sanità Pubblica, Roma, 2007 [http://www.asplazio.it/]

18. Decreto del Presidente del Consiglio dei Ministri 19 maggio 1995 "Schema generale di riferimento della Carta dei servizi pubblici sanitari", Gazzetta Ufficiale Repubblica Italiana 31 maggio 1995, n. 125, Supplemento Ordinario.

19. Legge 27 dicembre 2006, n. 296 "Disposizioni per la formazione del bilancio annuale e pluriennale dello Stato (legge finanziaria
2007)", Gazzetta Ufficiale Repubblica Italiana n. 299 del 27 dicembre 2006 - Supplemento Ordinario n. 244.

20. Carter AJ, Grierson R. The impact of ambulance diversion on EMS resource availability. Prehosp Emerg Care 2007; 11(4): 421426.

21. Sprivulis $\mathrm{P}$ et al. Internet accessibile emergency department workload information reduces ambulance diversion. Prehosp Emerg Care 2005; 9(3): 285-291.

22. Solberg LI, Asplin BR, Weinick RM, Magid DJ. ED crowding: consensus development of potential measures. Ann Emerg Med 2003; 42(6): 824-834.

23. Victor CR, Peacock JL, Chazot C, Walsh S, Holmes D. Who calls 999 and why? A survey of the emergency workload of the London Ambulance Service. J Accid Emerg Med 1999; 16: 174-178.

24. McConnel CE, Wilson RW. The demand for prehospital emergency services in an aging society. Soc Sci Med 1998; 46: 1027-1031.

25. Chan L, Reilly KM, Salluzzo RF. Variables that affect patient throughput times in an academic emergency department. Am J Med Qual 1997; 12(4): 183-186.

26. Downing A, Wilson RC, Cooke MW. Which patients spend more than 4 hours in the Accident and Emergency department. J Public Health (Oxf) 2004; 26(2): 172-176.

27. Krochmal P, Riley TA. Icreased health care costs associated with ED overcrowding. Am J Emerg Med 1994; 12(3): 265-266;

28. Hjälte L, Suserud B.O, Herlitz J, Karlberg I. Why are people without medical needs transported by ambulance? A study indications for pre-hospital care. Eur J Emerg Med 2007; 14(3): 151-156

29. Asaro PV, Lewis LM, Boxerman SB. The impact of imput and output factors on emergency department throughput. Acad Emerg Med 2007; 14(3): 235-242.

30. Williams RM. The costs of visits to emergency departments. N Engl J Med 1996; 334: 642-646.

31. South Australian Health Commission \& Commonwealth Department of Health and Family Services. Outpatient costing and classification study incorporating the developmental ambulatory classification system evaluation. Appendix, 7. 1998.

32. Spirivulis P. Pilot study of metropolitan emergency department workload complexity. Emerg Med Australasia 2004; 16 : 59-64.

33. Rucker DW, Edwards RA, Burstin HR, O'Neil AC, Brennan TA. Patient specific predictors of ambulance use. Ann Emerg Med 1997; 29: 484-491.

\section{ABSTRACT}

Objectives: To examine patient's characteristics associated with ED arrival mode, and to determine EMS impact on ED clinical resource use, workload and crowding. Methods: This is a retrospective study of patients seen at Sant'Andrea Hospital ED. Comparison focused on visit characteristics, and on resource use.

Results: The use of EMS ambulance confirms association to older age, higher rate of hospital admission, longer length of stay, and severity of injury. Moreover our data show that ambulance referred patients are triaged into a higher acuity category and have a greater intensive care unit admission.

Conclusion: Ambulance arrivals have a significant impact on ED resource use, workload and crowding. 